East African Medical Journal Vol. 81 No. 3 March 2004

OBSTETRIC PERFORMANCE OF WOMEN AGED OVER FORTY YEARS

E. O. Orji, FMCOG., FWACS., Senior Lecturer/Consultant Obstetrician and Gynaecologist and V. I. Ndububa, MBBS., FWACS, Senior Registrar, Department of Obstetrics, Gynaecology and Perinatology, College of Health Sciences, Obafemi Awolowo University, Ile-Ife, Nigeria

Request for reprints to: Dr. E. O. Orji, Department of Obstetrics, Gynaecology and Perinatology, College of Health Sciences, Obafemi Awolowo University, Ile-Ife, Nigeria

\title{
OBSTETRIC PERFORMANCE OF WOMEN AGED OVER FORTY YEARS
}

\author{
E. O. ORJI and V. I. NDUBUBA
}

\begin{abstract}
Background: Advanced age and parity constitute two major factors in the outcome of pregnancy and labour management both in the developed and developing countries. Objective: To examine pregnancy outcomes in women aged 40 years and above with the view of proffering solution to some of the problems encountered.

Design: A case control retrospective study.

Setting: Obafemi Awolowo University Teaching Hospital, lle-lfe, Nigeria from 1st January, 1995 to 31st December, 1999.

Subjects: Three hundred and three women who delivered at 40 years of age or above. The control group comprised of 303 women who delivered between 20 and 29 years during the five years period.

Main outcome measures: Gestational age at delivery, birth weight, mode and type of delivery, pregnancy and birth outcome.

Results: This showed a significant increase in prematurity, low birth weight, medical complications, operative deliveries (Caesarean section, vacuum and forceps), birth asphyxia and perinatal deaths all at $\mathbf{P}<0.05$.

Conclusion: There is a poor pregnancy outcome at fourty years and above. Patients need to be counselled for care in a specialised centre.
\end{abstract}

\section{INTRODUCTION}

Childbearing after the age of 40 years continues to be prevalent because of the high incidence of grand multiparity in our environment and the tendency to delay childbearing in pursuance of professional careers(1-4). Pregnancy at advanced maternal age has been regarded as high risk because of the associated increase in both maternal and perinatal morbidity and mortality(2-5). However, recent literature suggests that when underlying maternal disease conditions such as hypertension and diabetes are taken into account the risks are minimal and the overall neonatal outcome do not appear to be significantly affected(6-10).

Primigravid women after the age of 40 years and above are often well-educated professionals who purposely have delayed childbearing and who want as little distraction as possible(3). They often require special counselling concerning their risks so that they can make informed decisions. Previous data on this topic is composed largely of multiparous patients who have many unique problems that often are unrelated to the problems of the nulliparous women. Thus the results from these studies may be unhelpful to physicians counselling primigravid women about pregnancy outcome at an advanced age. In our study the results were stratified by parity, which is an important confounder.

This study was undertaken to identify the problems of pregnant women aged 40 years or above during pregnancy and labour at the Obafemi Awolowo University Teaching Hospitals Complex (O.A.U.T.H.C.), lle-lfe and to identify the ways of improving the maternal and perinatal outcome.

\section{MATERIALS AND METHODS}

This retrospective analysis of the pregnancy outcome of women aged 40 years or above covered a five year period from 15th January, 1995 to 31st December, 1999 at the Obafemi Awolowo University Teaching Hospitals Complex (O.A.U.T.H.C.), lle-lfe. Case notes of 303 women aged 40 years or above and 303 controls, which comprised of women aged between 20 and 29 years who delivered during the study period were analysed. The information obtained included the age at delivery, literacy level, complications during pregnancy and labour, mode of delivery, maternal mortality and foetal outcome. In our study the results were stratified by parity, which is an important confounder.

\section{RESULTS}

During the study period there were 4,691 deliveries of which 303 were aged 40 years or above giving the study population an incidence of $6.5 \%$ of the total population. The control population consisted of 303 parity-matched women who delivered between 20 and 29 years during the study period. Two hundred and sixty five women $(87.5 \%)$ were aged 40 years while $38(12.5 \%)$ were aged 45-49 years. Twenty eight $(9.3 \%)$ were nulliparas, 127 (41.9\%) were para $1-4,148(48.8 \%)$ were para 5-7. 
Table 1

Pregnancy and delivery characteristics

\begin{tabular}{|c|c|c|c|c|c|c|}
\hline & \multicolumn{3}{|c|}{ Nulliparous } & \multicolumn{3}{|c|}{ Multiparous } \\
\hline & $\geq 40$ Years & 20-29 Years & P-value & $\geq 40$ Years & 20-29 Years & P-value \\
\hline $\begin{array}{l}\text { Mean Gestational } \\
\text { Age (days) }\end{array}$ & $273.4 \pm 0.4$ & $178.5 \pm 0.1$ & 0.002 & $274.9 \pm 0.2$ & $278.3 \pm 0.1$ & 0.004 \\
\hline $\begin{array}{l}\text { Mean Birth } \\
\text { Weight }(\mathrm{g})\end{array}$ & $2901 \pm 10$ & $3197 \pm 1$ & 0.03 & $3211 \pm 5$ & $3387 \pm 1$ & 0.008 \\
\hline Delivery Mode (\%) & & & & & & \\
\hline Caesarean & 47.0 & 22.5 & 0.02 & 29.6 & 17.8 & 0.02 \\
\hline Forceps & 4.5 & 3.1 & 0.04 & 1.2 & 0.8 & 0.05 \\
\hline Vacuum & 9.7 & 9.8 & 0.05 & 5.1 & 3.8 & 0.05 \\
\hline
\end{tabular}

Table 2

Pregnancy outcome of older mothers

\begin{tabular}{|c|c|c|c|c|c|c|}
\hline \multirow{2}{*}{$\begin{array}{l}\text { Outcome } \\
(\%)\end{array}$} & \multirow[b]{2}{*}{$\geq 40$ Years } & \multicolumn{2}{|l|}{ Nulliparous } & \multirow[b]{2}{*}{$\geq 40$ Years } & \multicolumn{2}{|l|}{ Multiparous } \\
\hline & & 20-29 Years & P-value & & 20-29 Years & P-value \\
\hline Anaemia & 5 & 6 & 0.22 & 14.3 & 7.1 & 0.03 \\
\hline Hypertension/Pre eclampsia & 10.6 & 6.8 & 0.03 & 5.3 & 2.3 & 0.06 \\
\hline Diabetes Mellitus & 2.6 & 0.5 & 0.04 & 1.4 & 0.9 & 0.04 \\
\hline Placenta Praevia & 16.0 & 18.8 & 0.05 & 9.2 & 5.7 & 0.03 \\
\hline Abruptio Placenta & 3.6 & 2.5 & 0.04 & 3.3 & 04 & 0.04 \\
\hline Multiple Pregnancy & 5.4 & 3.4 & 0.03 & 18.3 & 11.1 & 0.03 \\
\hline Malpresentations & 1.6 & 0.3 & 0.06 & 6.5 & 4.0 & 0.04 \\
\hline Prematurity & 1.4 & 0.9 & 0.04 & 5.7 & 2.9 & 0.04 \\
\hline Prolonged Pregnancy & 7.0 & 8.7 & 0.03 & 2.5 & 1.6 & 0.02 \\
\hline Obstructed Labour & 4.1 & 2.1 & 003 & 6.4 & 3.7 & 0.04 \\
\hline Prolonged Labour & 7.2 & 6.1 & 0.06 & 9.9 & 5.1 & 0.05 \\
\hline
\end{tabular}

Table 3

Neonatal complications in older mothers

\begin{tabular}{|c|c|c|c|c|c|c|}
\hline Apgar Score & $\begin{array}{l}\text { Nulliparous } \\
\geq 40 \text { Years }\end{array}$ & $20-29$ & Years P-value & $\geq 40$ Years & $\begin{array}{l}\text { Multiparous } \\
\text { 20-29 Years }\end{array}$ & P-value \\
\hline$<7$ at 1 Minute & 79 & 60 & 0.04 & 64 & 44 & 0.02 \\
\hline$<7$ at 5 Minutes & 61 & 35 & 0.03 & 23 & 19 & 0.04 \\
\hline Perinatal Deaths & 1.3 & 0.9 & 0.15 & 3.0 & 1.1 & 0.04 \\
\hline
\end{tabular}

In Table 1, the distribution by gestational characteristics is given for both the nulliparous and mutiparous in each age group. The most significant finding is that the Caesarean rate is significantly higher in the older nulliparous and older multiparous groups compared with their respective control groups. More nulliparous women aged 40 years had Caesarean section (47\%) compared to $29.6 \%$ among the older multiparous. Table 2, shows the various complications observed in pregnancy and labour. There were statistically significant increases in the medical, pregnancy and labour complications among the nulliparous aged 40 years or older compared with control groups. In Table 3, the rate of birth asphyxia (low 5-minute Apgar scores) was increased in the older nulliparous and multiparous group compared with their respective controls - the same was also true of perinatal mortality rate. More of the older nulliparous had lower Apgar scores both at 1 and 5 minutes respectively compared to older multiparous.

\section{DISCUSSION}

The older women in this study had a lower mean gestational age $(273.4 \pm 0.4)$ compared with the control population. This may reflect the tendency towards earlier delivery because of the anxiety of still birth in older nulliparous women who often have a long history 
of infertility and in whom the chances of subsequent pregnancy is reduced due to diminishing fertility $(1-4,6)$. The lower mean birth weight in the older mothers may also reflect lower mean gestational age at delivery, but the associated increased pregnancy complications discussed below may also be a contributory factor(2,3).

In this study, the incidence of Caesarean section and operative vaginal delivery in nulliparous women aged 40 years or above (Caesarean $47.0 \%$, operative vaginal delivery $12.9 \%$ ) is significantly higher than younger nulliparous controls (Caesarean 22.5\%, operative vaginal delivery $12.9 \%$ ). A similar finding is also observed in older multiparous group (caesarean $26.9 \%$, operative vaginal delivery $6.3 \%$ ) compared with their younger counterpart (Caesarean $17.8 \%$, operative vaginal delivery $4.6 \%$ ). The increased rate of operative delivery observed in older mothers can be attributed to the associated increase in pregnancy complications such as malpresentations and abnormal forces of labour. However malpresentation are common in older multiparous compared to older nulliparous as shown in Table 2. The higher caesarean section rate of $47 \%$ among older mothers while in agreement with reports from other centres(5-10), was markedly higher than 9.7\% reported in Sagamu, Ogun State, Nigeria(4). However within the same parous group there is no significant difference in the operative vaginal delivery.

This may de due to the fact that conditions likely to necessitate operative vaginal delivery may be more influenced by parity after controlling for age.

Though pregnancy complication such as hypertension, malpresentations, premature labour and prolonged labour were increased in the older women compared with control patients the number of these complications were small to make a categorical statement on this. These findings are however consistent with studies from other centres(5-8). However, complications such as anaemia and placenta praevia were not significantly increased in the older nulliparous group compared with control, but it is increased in the older multiparous. This would suggest that parity play an important role in the occurrence of anaemia and placenta praevia in the older mothers and agree with previous findings. The incidence of prolonged pregnancy is less in the older mothers and may reflect earlier intervention in view of the increased associated complication.

The Apgar scores at 1 and 5 minutes were better for the younger controls of both parous group compared to women aged 40 years and above but this did not show a very strong statistical significance. Similarly the elderly multiparous women had better Apgar scores than their nullliparous counterpart but this did not also show strong statistical significance. Also the younger multiparous women also had better Apgar scores than their nulliparous counterpart. In general the neonatal complications noted in the study were increased in the older patients compared with the younger controls but the increase in perinatal death was more noticeable in the multiparous groups. These results are consistent with previous reports(7-9). The lack of significant increase in perinatal mortality in the older nulliparous group over the nulliparous control could be attributed to the increased rate of elective Caesarean section performed in the former group so that the foetuses are not subjected to the labour complications mentioned before.

In conclusion, pregnant women aged 40 or over have a higher risk of caesarean section; not operative vaginal deliveries which are the same. This data highlights the need for proper counseling of such patients about their pregnancy expectations and possible outcomes as well as the need for delivery in specialised centres.

\section{ACKNOWLEDGEMENT}

To Medical Records Staff for their assistance in data collection.

\section{REFERENCES}

1. Anate, M. and Akeredolu, O. Pregnancy outcome in elderly primigravida in Ilorin, Nigeria. Nig. Med. J. 1995; 29:14-16.

2. Paneye, A. A. The influence of parity on the mode of delivery. Antr. Afri. J. Med. 1988; 34:26-28.

3. Gilbert, W. M., Nesbitt, T. S. and Danielson, B. Childbearing beyond age 40: pregnancy outcome in 24,032 cases. Obstet. Gynaecol. 1999; 93:9-14.

4. Sule-Odu, A. O. Obstetric performance of women aged forty and over. Nig. Med. Pract. 1999; 37: 3/4:38-40.

5. Bianco, A., Stone, J., Lynch, L., Lapiski, R., Berkowitz, G. and Berkolvitz, R. L. Pregnancy outcome at age 40 or older. Obstet. Gynaecol. 1996; 87:917-922.

6. Cnattingius, S., Forman, M. R., Berendes, H. W. and Isotalo, L. Delayed childbearing and risk of adverse perinatal outcome. A population-based study. JAMA. 1992; 268:886-890.

7. Edge, V. and Laros, R. K. Pregnancy outcome in multiparous women aged 35 or older. Amer. J. Obstet. Gynaecol. 1993; 168:1881-1885.

8. Prysak, M., Lorenz, R. P. and Kisley, A. Pregnancy outcome in multiparous women aged 35 or older. Obstet. Gynaecol. 1995; 85:65-70.

9. Ekblad, U. and Vilpa, T. Pregnancy outcome in women over forty. Ann. Chir. Gynaecol Supp. 1994; 208:68-71.

10. Gordon, D., Milberg, J. Daling, J. and Hickok, D. Advanced maternal age as a risk factor for caesarean delivery. Obstet. Gynaecol. 1991; 77:493-497. 